\title{
Corporate Culture's Role on Digital Transformation, Lesson Learnt for Vietnam Businesses
}

\author{
Phan Y LAN* \\ Department of Management Science and Law - School of Economics and Management \\ Hanoi University of Science and Technology, Hanoi, Vietnam \\ *Corresponding: lan.phany@ hust.edu.vn
}

\begin{abstract}
Digital transformation is a concept born in the internet booming era, which is gaining popularity in recent years, describing the application of digital technology to all aspects of businesses. If effective, this activity will completely change the way a business operates, increase cooperation efficiency, optimize work efficiency and bring value to customers. The 4.0 revolution and digital transformation will create development opportunities for businesses in the world and in Vietnam in the coming decades. To adapt, companies must fundamentally change the way they operate, be willing to accept cultural change, and rethink the status quo. The purpose of this paper is to give an overview of corporate culture, levels of corporate culture, overview of digital transformation, steps in the digital transformation process. The paper also outlines the characteristics of a digital culture to match the digital transformation process. The main research results of this paper show the importance of corporate culture to the digital transformation process, thereby providing lessons for Vietnamese businesses in digital transformation, creating an important foundation for Vietnam's successful implementation of the digital economy in the future.
\end{abstract}

\section{Research purpose:}

The purpose of the research is to give an overview of corporate culture, digital transformation and the influence of corporate culture in the digital transformation process. From there, the paper determines the role of culture in the digital transformation process and provides lessons for businesses in Vietnam in the digital transformation process.

\section{Research motivation:}

Digital transformation is currently a matter of concern for the state, ministries, sectors, businesses and researchers. The study of culture at enterprises for digital transformation is an urgent issue, because digital transformation is not simply an effort to invest in applying information technology but a comprehensive and profound transformation. In order to fully exploit the power of the booming technological progress to improve efficiency, competitiveness and create a basic foundation for a long-term development journey, businesses must realize the importance of culture in the digital transformation process.

Research design, approach and method:

- Methods of collecting and analyzing documents: collecting information and documents from many different sources such as books, newspapers, magazines, television, radio, internet, ... and from many other sources to ensure that the amount of information collected is accurate and complete.

- Specific method: proof + analysis.

Main findings:

The main research result of this paper shows that corporate culture, not technology, is an important factor for digital transformation, thereby providing lessons for Vietnamese businesses in digital transformation, creating an important foundation for Vietnam to successfully implement the digital economy in the future.

\section{Practical/managerial implications:}

Businesses in Vietnam who want to overcome the challenges and barriers when moving from traditional culture to digital culture require efforts from leaders and employees. Vietnamese businesses need to put digital culture in their transformation strategy. A correct and sufficient awareness of all factors thereby creating a new mindset to make the digital transformation process easier.

Keywords: corporate culture, digital transformation, digital culture, adaptation, articulate, activate, align 


\section{INTRODUCTION}

In recent years, "digital transformation" is a keyword that has been constantly mentioned and is mentioned more and more from the enterprise level to the ministries, sectors and countries. The story of "digital transformation" in Vietnam has become more exciting since mid-2020, when the Prime Minister approved the National Digital Transformation Program, and especially "hot" when the COVID-19 pandemic- 19 began to explode on a global scale. Digital transformation is a matter of concern to most businesses and managers at the moment because of its great impact on the market. This leads organizations to take early action to adapt to this period. A big problem is that we are often not ready to accept changes imposed by old thinking and habits ( $\mathrm{Vu}$ Minh Khuong, 2019). A common misconception is that if a company upgrades its technology, then digital transformation will take place. The reality, however, is that digital transformation is not about software or technology - it's about organizational adaptability. To thrive in this time of change, every business must adapt quickly. Corporate culture can be the single most important determinant of that business's success to enable rapid adjustment to new conditions and incentivize employees to adopt new digital transformations. To keep pace with the change driven by digital transformation, organizations must be agile and adaptable, and organizational culture is critical to the success of any digital initiative. which number.

Digital transformation is distinguished from previous ITenabled business changes primarily in its velocity and holistic nature (Bharadwaj et al. 2013; Porter and Heppelmann 2014). Digital technologies accelerate innovation, disruption and competition in the business environment (Downes and Nunes 2013; Porter and Heppelmann 2014; Westerman et al. 2011). To cope with rapidly changing environmental conditions and the acceleration of these changes due to technological innovation, organizations need to fundamentally transform and restructure their organizations in order to survive. in a disrupted environment (Downes and Nunes 2013; Porter and Heppelmann 2014).

Therefore, digital transformation goes beyond the mere digitization of products and services, and companies need to redefine their industries and value propositions (Porter and Heppelmann 2014). Therefore, digital transformation can be defined as organizational changes with IT support including the digitization of products, services, core processes, customer touch points and business models (Fichman et al. al. 2014; Hess et al. 2016). To carry out such fundamental business transformations, organizations are forced to develop digital transformation strategies, set up digitalization initiatives, and deploy IT infrastructure investments to capture key opportunities. Emerging societies are opened up by new technologies
(Bharadwaj et al. 2013; Downes and Nunes 2013; Hess et al. 2016).

Scholars from many disciplines and fields of study agree that culture fundamentally impacts the success of business transformations. Philip and McKeown (2004) argue that business transformation is about bringing about radical changes in corporate culture in terms of structure, processes and, above all, people's attitudes, beliefs and behaviours. As suggested by Venkatraman (1994), organizational and cultural transformation is essential to fully exploit the benefits of new IT deployments, the establishment of a digital mindset, and cultural change driven by which is considered necessary for successful digital transformation (Fitzgerald et al. 2014)

\section{OVERVIEW OF CORPORATE CULTURE} 2.1 What is corporate culture?

Deal \& Kennedy (2000) defines: To put it simply, Corporate culture is "the way things are done around here".

And in 2004, Needle said that: Corporate culture also includes vision, core values, standards, systems, symbols, language, assumptions, beliefs as well as behaviors of the company. members in the organization.

According to N.Demetr - French sociologist: "Corporate culture - it is the system of concepts, symbols, values, and behavioral patterns that are recognized by all members of the enterprise. know and follow".

There are many concepts of Corporate Culture, but this article finds that one concept is considered to be the most general and popular of Edgar H.Schein, (2004) an American sociologist: "Corporate culture: is a set of methods and rules for dealing with problems of external adaptation and internal unity among employees, rules that have worked in the past and are still relevant today. These rules and procedures are the starting point in the selection of appropriate action, analysis and decisionmaking by employees. The members of the corporate organization did not think twice about the meaning of these rules and procedures, but considered them right from the start."

From the concept of Edgar H. Shein, we can understand that corporate culture is formed and developed in parallel with the development process of the business, not only the communication culture but also the price. core values, rules, management style, business methods and behavior and attitudes of all members of the enterprise. The importance of corporate culture comes into play when it helps businesses adapt to changes in the external environment. If facilities and equipment are the "body" of the business, and the corporate culture is the "soul" of the business. Corporate culture is an intangible asset of the enterprise, contributing to the great strength of the enterprise. Corporate culture is deeply rooted in trust, so it plays an important role in the implementation of the 
organization's goals and tasks. Corporate culture creates strength from within the collective, within each individual.

An enterprise with a strong culture and in line with the long-term goals and strategies that the business has set out creates employee pride in the business, from which everyone always lives, strives and fights to the fullest. volunteering for the common goal of the business, making it easier for leaders to manage the business, making employees more comfortable and proactive in orienting their way of thinking and doing, create a competitive advantage for businesses.

Corporate culture inherits, preserves the identity of the business through many generations of members, creates the possibility of sustainable development of the enterprise, and transmits the consciousness and values of the organization to the members of the organization. That is, culture creates a shared commitment to the goals and values of the organization, it is greater than the interests of each individual in that organization, culture creates the stability of the organization

\subsection{Levels of corporate culture}

According to Edgar H.Shein (2004), corporate culture is divided into three levels:

\section{a. First level}

This is the cultural level that can be seen at first contact including the phenomena and things that a person can hear, see and feel when in contact with an unfamiliar organization: Architecture, way arrange; product technology; Organizational structure, departments of the enterprise; Documents stipulating operating principles of enterprises; Annual ceremonies and festivals; Icons, logos, slogans, promotional materials of the business; Language, dress, vehicle, title, emotional expression, common behavior of members and working groups in the enterprise; Organizational stories and myths; Forms and designs of products; Attitudes and behavior of business members.

This is the most recognizable, most perceptible level of culture. This level of culture has the common characteristic that it is heavily influenced by the nature of the company's business, the leader's point of view, etc. However, this level of culture is easy to change and rarely shows the real value in corporate culture.

\section{b. Second level}

Declared values (Business strategy, goals, philosophy of the business, etc.)

Every enterprise has its own regulations, principles, philosophies, strategies and goals, which are guidelines for the activities of all employees and are often published to the public. These are also the declared values, a part of the corporate culture. "Declared values" are also tangible because they can be identified and expressed clearly and precisely. They perform the function of instructing members of the enterprise how to deal with some basic situations and training the behavior of new members in the corporate environment.

\section{c. Third level}

General concepts (unconscious beliefs, perceptions, thoughts and feelings, implicitly recognized in the business)

In any cultural level (national culture, business culture, corporate culture...) there are common concepts, formed and exist for a long time, they are deeply ingrained in the mind. accepted by most members of that culture and has become a recognized tacit.

When members share and act in accordance with that common concept, it will be difficult for them to accept opposite behaviors.

All three levels of corporate culture are always intertwined and compatible with each other towards expressing the unique characteristics of that business.

\subsection{The role of corporate culture}

Some benefits that make the importance of corporate culture can be summarized as:

- Create a competitive advantage

- Attract talent, strengthen the loyalty of employees to the business.

- Create identity, unique identity of the organization, distinguishing one organization from another

- Encourage innovation and creativity

- As a strategy implementation tool

\section{OVERVIEW OF DIGITAL TRANSFORMATION} 3.1 What is Digital Transformation?

Gartner's IT Glossary defines Digital Transformation as the application of digital technologies to transform a business model and provide new revenue and value creation opportunities.

Digital transformation refers to the customer-driven strategic business transformation that requires crosscutting organizational change as well as the implementation of digital technologies. In reality, digital transformation requires the organization to deal better with change overall, essentially making change a core competency as the enterprise (Jacson Bloomberg, 2018) According to Microsoft (2017): "Digital transformation holds the potential to transform every manufacturing operation. Process means transformation converting traditional processes to more efficient digital systems that can increase efficiency dramatically, improving all aspects of the operations. Product and service transformation means creating new value-add services that can both improve the manufacturing environment and the customer experience while opening new revenue streams".

Defining digital transformation IBM: "Digital transformation takes a customer-driven, digital-first approach to all aspects of a business, from its business models to customer experiences to processes and operations. It uses AI, automation, hybrid cloud and 
other digital technologies to leverage data and drive intelligent workflows, faster and smarter decisionmaking, and real-time response to market disruptions. And ultimately, it changes customer expectations and creates new business opportunities".

In Vietnam, the commonly used concept of "Digital Transformation" is the concept of FPT: Digital transformation is the process of changing from a traditional business model to a digital one by applying new technologies such as data. big data (Big Data), Internet of Things (IoT), cloud computing (Cloud)... to change the way of operating, leadership, working process, company culture.

Lisay Herbert (2017) "Real digital transformation isn't about getting your company to use a specific set new technology; it's about your company's ability to react and succeedtuly utilze new technologies and procedures -now and in the future".

Through the above concepts, it can be said that digital transformation is the integration of digital technologies into all areas of an enterprise, taking advantage of technologies to fundamentally change the way it operates, the business model. business and deliver new value to its customers and accelerate business operations. Digital transformation is also a change in the culture of businesses, requiring businesses to constantly change, try new things and freely accept failures.

Digital transformation consists of the following stages: (i) information digitization - the creation of digital representations of physical objects; (ii) digitization of the organization - is the transformation or creation of business models or operating models with data and digital technology, and (iii) comprehensive transformation of the organization from thinking, models, leadership, activities to corporate culture.

\subsection{Steps in the digital transformation process}

To carry out digital transformation, businesses need to take the following 5 steps:

\section{Assess the current state and wishes of the business}

Assessing the current state of the business is the first step in the digital transformation process. The first step in the digital transformation process is for leaders to clearly identify what is happening in the organization and the trends in the market. From there, choose the right direction for your business.

Where are the current unmet needs? How will upgrading the technology system contribute to the company's development goals? Where will digital technology be right for businesses? These are important questions during the assessment period.

\section{Assess your business' readiness for digital transformation}

After having an overview of the status quo, the next step in the digital transformation process is to assess the readiness of the business. This job requires businesses to meet two factors: people and data.

- Human factors

This is the most important factor. After all, technology is just a kind of support tool. No matter how smart the tool is, if the user does not have a change mindset, it cannot be effective. In other words, the success of digital transformation will be determined right in the mindset and vision from leadership levels to all levels of employees.

- Data element

Data is an integral part of building digital transformation. If used well, data will create a springboard to help businesses transform digitally faster. However, in addition to analyzing existing data within the business, executives also need to pay attention to the data of their strategic partners as well as their competitors. From there, have an overview of the business value chain before entering the digital transformation race.

Review the process to make the necessary changes and select the right technology

This is an opportunity for businesses to look back to see if they are fully ready for digital transformation. The review allows the business to know which technologies need to be improved? Where is the "outdated" process that needs to be changed? Which stage is not ready and how to solve it? Then make the appropriate adjustments. Again, decision makers should not rely on personal intuitive inferences, but need to look at actual data to find the right direction for the business.

\section{Create an open feedback culture}

Digital transformation cannot be successful if it only comes from business leaders. Open communication is a key component of building a digital transformation process. Manager and employee feedback also plays an important role. Based on this feedback, leaders can make changes to optimize training effectiveness. To encourage constructive feedback, foster open discussions, open spirits, and collaboration.

Commitment to digital transformation of the leadership and the whole business

Successful businesses in digital transformation say that changes in corporate culture are more difficult than changes in technology. In order for all employees in the organization to understand that digital transformation is an important activity, leaders need to make it clear that digital transformation is a central strategy of the business. This needs to be demonstrated through the actions and plans of the company as well as the establishment of strategic teams in digital transformation. All of which signals the organization's commitment to the issue.

Like other major transformations, digital transformation requires the right culture to go hand in hand with the execution of the transformation strategy. 
Therefore, in order to have a suitable culture in the digital transformation period, it is necessary for enterprises to build a digital culture with different characteristics from the traditional corporate culture.

\subsection{Digital culture and characteristics of digital culture}

Changing a long-standing culture in the business is a difficult thing, but it must be determined that change to meet the requirements of the "digital age" is urgent, first requiring leaders as well as must "get over yourself". The culture of the digital transformation era has new characteristics. First is the nature of "first digital thinking", then fast and flexible adaptation, innovation, data-driven decision making, customer-centricity, collaboration, and an open culture (Capgemini, 2017)

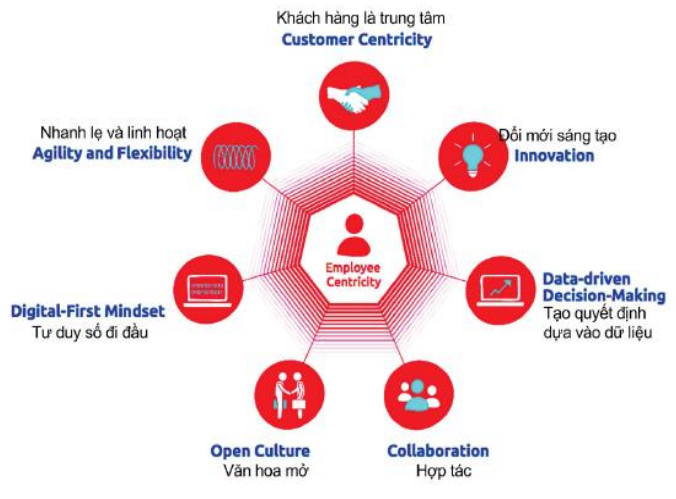

Fig.1. 7 characteristics of culture in the digital transformation period

(Source: Capgemini, 2017)

\section{Customer centricity}

The digital era has turned to a "customer-centric" orientation. The company may change its business model and adjust to the new market, but the customer will still be the most important decision maker in this change process.

Businesses need to build a customer-centric mindset, customers are "relatives" instead of "gods". Putting customers first, businesses can ensure digital transformation is supported by customers themselves.

\section{Innovation}

Innovation is a must in the digital transformation competition. With each passing day, new trends, new technologies, new people appear. Innovative thinking will help both leaders and employees keep up with today's strong digital transformation.

To build that mindset, businesses can regularly organize creativity contests, encouraging employees to propose new ideas. The leader is the pioneer, and must also be the one to listen to the suggestions and support the new initiatives of the employees.
When all departments are linked through the process, the corporate culture will become stronger, stronger. Working in an open environment, all departments are related to each other, can support and help each other in work. This allows businesses to work more smoothly.

\section{Open culture}

Open thinking helps businesses have a broader perspective, grasp current trends - the core element of digital transformation. Expand your horizons beyond traditional limitations to focus on adding as much value as possible, being willing to learn and change, and rightly accept failure. This is a striking difference from traditional culture. In a flat and connected world, thinking outwardly, sharing benefits for mutual benefit is the way to help businesses be flexible and adapt to any change. The sharing economy is a typical model for the digital age.

\section{Digital first Mindset}

Digital transformation must, of course, be associated with digital thinking. Not only digitize processes and operations, but also digitize thinking. One of the benefits of digital transformation is the ability to track and analyze data. This allows businesses to use data to optimize business strategies and tactics for better results. In addition, making decisions based on data also helps businesses better understand customer needs, thereby creating timely, appropriate and flexible feedback and improvements.

Digital transformation does not only depend on technology, but people are still the decisive factor. Enterprises will only implement digital transformation successfully if and only if the entire HR team, including leaders, must overcome the "traps" in thinking - things that can slow down or "derail" "Enterprise digital transformation initiatives.

\section{Agility Flexibility}

A digital transformation culture requires flexibility and sensitivity. This forces the work processes and steps to be smooth and fast. In addition, businesses also need to be flexible in absorbing opinions and feedback.

Above all, businesses can only survive in the intense flow of digital transformation only if they are really flexible and timely to adapt to changes and new things.

\section{ROLE OF CORPORATE CULTURE IN DIGITAL TRANSFORMATION, LESSONS FOR VIETNAM}

4.1 Impact of corporate culture in digital transformation

It can be said that digital transformation culture is a huge challenge for businesses today. Therefore, businesses need to pay special attention to building and changing culture to always innovate from thinking to acting to adapt to the rapidly changing era and increasingly fierce competition. 
Being a digital business is not just about having products, services and customer interactions on digital technology, but also having all core activities driven by technology. Therefore, it requires a great change to the actions of employees, as well as the individual's behavior towards others inside and outside the organization. Thus, the traditional way of working will clash with the new way of working. Cultural immersion is important. A healthy culture provides guidelines - or codes of conduct - for each person in the organization to act towards the organization's goals and strategy. So we see there are 3 important reasons to make sure to instill a digital culture in the digital transformation journey (Jim Hemerling, Julie Kilmann, Martin Danoesastro, Liza Stutts and Cailin Ahern, 2018)

- Digital transformation is likely to fail if the role of culture is underestimated

Capgemini (2017)- The leading company in technology and consulting services has conducted a survey with 1,700 senior leaders, managers and employees in 350 businesses. Accordingly, up to $62 \%$ of those surveyed consider cultural issues the number one barrier in digital transformation. Another report from BCG - Boston Consulting Group also said that nearly $80 \%$ of companies maintain strong performance thanks to a strong focus on culture during digital transformation.

- A culture that's right for digital transformation will dramatically boost employees' ability to create results

Digital transformation businesses grow faster than traditional businesses thanks to a flatter hierarchy. This means employees are more empowered and, as a result, faster decision-making. Culture in this stage is seen as a set of rules that guide employees and enable them to produce quick, productive results.

- A business that develops a culture suitable for digital transformation is often easy to attract talent

Cultural ethos will be especially important in attracting talent with the right strengths and traits, especially as demand outstrips supply.

\subsection{Lessons learned for Vietnamese enterprises. a. Current status of digital transformation in Vietnam}

In Vietnam, in recent years, the digital transformation process has begun to take place, especially in industries such as finance, transportation, tourism... The government and authorities at all levels are making efforts to build E-Government towards Digital Government. Many cities are also intending to build smart cities with new technology platforms... However, Vietnamese businesses in general, especially small and medium enterprises, are still not aware of the role of transformation. change numbers in the industrial revolution 4.0 .
Recently, Cisco (a global networking company) has released the report "Digital Development Index of Small and Medium Enterprises in Asia - Pacific" [2], covering over 1,340 enterprises. in the region in general and 50 enterprises in Vietnam in particular. In Vietnam, small and medium-sized enterprises are facing barriers in the conversion process such as lack of digital skills and human resources (17\%), lack of a strong enough IT platform to enable conversion $(16,7 \%)$, lack of digital thinking or cultural and digital challenges in businesses (15.7\%) [3]... However, the report also points out that SMEs are and small businesses in Vietnam are initially investing in cloud technology (18\%), network security $(12.7 \%)$, upgrading software and hardware for colleges (10.7\%) (Capgemini, 2017)

The long-standing habits that create a "corporate culture" that people often say "inertia" are very difficult things to change. It creates great barriers and is a huge challenge for businesses in digital transformation.

- Capability barriers: there may be complacency with the past, have been successful through change but do not feel the need to continue to change immediately. This is self-contained and makes the business incapable of transformation.

- $\quad$ Speed barrier: leadership does not respond to the changing speed of the times or does not require the speed of employees to respond, but what is more dangerous is not being aware of the speed of change of competitors, creating terrible threat to your own business.

- Consciousness barrier: leaders often require employees to change while being permissive. If leaders do not have a sense of pioneering change, it often creates a "metaphorical" collective inertia behind the curtain of slogans.

- Internal barriers: newly changed apparatus often has "out of synchronicity" between parts, if not well controlled, it can create suspicion, wait for each other or non-cooperation can lead to come to each other's feet...

\section{b.Orientation}

The above current habits and barriers, if any, are often the legacy of a business management method and of the leaders themselves, so building a new culture is suitable for the key digital transformation period. is the transformation of an entire corporate culture. Achieving success in changing corporate culture requires the consensus of the entire employee system, in which leaders must always be pioneers, role models and play a core role in the success of the company. that work. Leaders must clearly see the importance of culture and identify cultural change as a task in the digital transformation process.

The first is a matter of awareness and thinking of leaders. Because leaders and employees are not prepared or motivated to adapt to the new way of working. Changing 
culture requires a lot of effort and time. Leaders must not only communicate the strategic vision of the organization, but also provide employees with the means to understand and align their work accordingly. To do this, there are 5 factors that leaders in Vietnamese enterprises need to change to be able to act and apply right in their businesses as follows:

- Leadership behavior - Sensibility in applying technology and digital vision, Having a specific strategy and action plan, Having a ready mindset and ability to influence those around you to agree with me.

- Employee Engagement - Changing the company's vision and internal operations associated with the digital era, creating associations dedicated to digital transformation, and always encouraging employees to cultivate "Digital thinking" and continuously learning new technologies.

- A culture of collaboration, trust and achievement - Rewarding and recognizing individuals for doing the right thing, creating empowered and influential small groups to drive change action for the entire world. Staff.

- Diversity and inclusion - Creating a diverse and gender inclusive workplace environment; between generations, removing barriers of hierarchy and bias.

- Corporate Responsibility - Enterprises must play a key role in making the transition: supporting infrastructure, proper budgeting, allocation of responsibilities and proper management.

Changing a long-standing culture in the business is a difficult thing, but it must be determined that change to meet the requirements of the "digital age" is urgent, first requiring leaders as well as must "get over yourself". When Leaders have changed their perception and thinking, building a digital culture has become a decisive factor in the digital transformation process. Vietnamese businesses need to put digital culture in their transformation strategy. A correct and sufficient awareness of all factors creates a new mindset that makes the digital transformation process easier. Activities that businesses need to do immediately to achieve a digital culture:

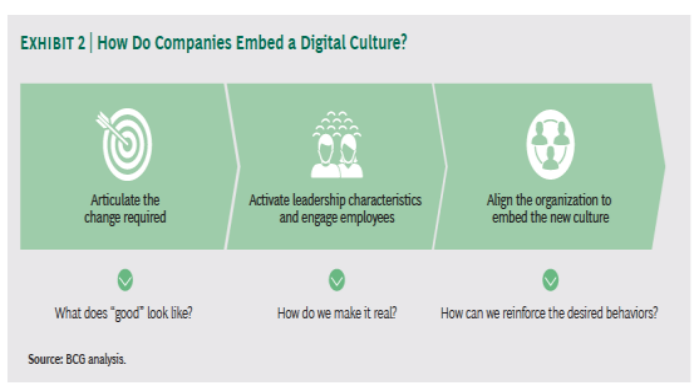

Fig. 2: How do companies embed a digital culture? Nguồn:Boston Consulting Group, 2018

- Articulte the change required: When a company clearly identifies the behaviors that are appropriate for the company, and employees respect and adhere to them, the company can clearly see a strong culture, and then will collect plan was successful. This is a process that requires leadership, a lot of work, to finally have a "cultural code" and direct employees to practice it.

- Activate leadership characteristics and engage employee: Every high-productivity culture requires strong leadership and employee engagement. In a digital culture, teams need to act autonomously, and everyone needs to practice being critical. But simply saying no can't promote such behaviors, leaders at all levels must stick to them and clearly demonstrate them.

- Aligning the organization to embed a new culture: Since digital transformation represents the departure of the way a traditional business model works, companies often experiment through a pilot program designed by excellent leaders. To elicit new leadership behaviors, companies adjust their performance metrics as well as adjust their areas of accountability. Companies also change decision-making powers to promote decision-making. Once the pilot is successful, those senior leaders are ready to launch the transformation.

The big problem lies in the management and employees, who are not prepared or motivated to adapt to the new working style. Changing culture requires a lot of effort and time. Many issues also need to be reviewed and adjusted, including operating models, organizational design, productivity management, etc. as well as many programs and initiatives that need to be implemented.

\section{CONCLUSION}

We live in a digital, global, and hyper-connected world, characterized by social and technological change, where the constant emergence of new "players" in the marketplace environment, mobility, and constant 
connectivity make a big impact. Today, digital transformation is not just an option. Companies need to get out of their comfort zone, reinvent themselves, and compete in a world dominated by innovative technologies. Digital transformation is an opportunity and also a challenge for businesses in the world in general and Vietnamese businesses in particular. Therefore, businesses, or administrators need to be prepared for this change that will take place continuously and very difficult. Through the study of corporate culture and digital transformation, the article has pointed out the importance of culture in the digital transformation process of businesses. To succeed in digital transformation, it must start with culture. Culture consists of the values and characteristic set of behaviors that define the way things are done in an organization. Vietnamese enterprises that want to successfully transform digitally must overcome cultural barriers, need the consensus of the entire employee system, in which the leader must always be the pioneer. role model and play the core role.

\section{REFERENCES}

[1] Capgemini Digital Transformation Institute, 2017, "The Digital Culture Challenge: Closing the Employee-Leadership Gap"

[2] https://www.capgemini.com/wpcontent/uploads/2017/12/dti_digitalculture_report.pdf

[3] Cisco, 2020 Asia Pacific SMB Digital Maturity Study

[4] https://www.cisco.com/c/en_vn/solutions/smallbusiness/resource-center.html

[5] Duong Thi Lieu, 2012, Business Culture, National Economics University Publishing House

[6] Eva Hartl, Thomas Hess, 2017, The role of Cultural values for Digital Transformation: Insight from A Delphi Study, Twenty-third Americas Conference on Information Systems, Boston, 2017

[7] Edgar. H Shein, 2010, Organizational Culture and Leadership, Jossey-Bass, 3

[8] Government (2020), National Digital Transformation Program to 2025 , orientation to 2030.

[9] Lindsay Herbert, 2017, Digital Transformation: Build Your Organization's Future for the Innovation Age, Bloomsbury publishing, US

[10] Jim Hemerling, Julie Kilmann, Martin Danoesastro, Liza Stutts, and Cailin Ahern (2018) It's Not a Digital Transformation Without a Digital Culture

[11] https://www.bcg.com/publications/2018/not-digitaltransformation-without-digital-culture
[12] Jacson
Bloomberg,
2018 ,
Digitization,

Digitalization, And Digital Transformation: Confuse Them At Your Peril

[13] https://www.forbes.com/sites/jasonbloomberg/2018/ 04/29/digitization-digitalization-and-digital-

transformation-confuse-them-at-your-

peril/?sh=64782c512f2c
[14] Lê Ngọc Quang, 2020, Corporate culture in digital transformation, https://coact.vn/van-hoa-doanh-nghieptrong-chuyen-doi-so/

[15] Microsoft., 2017, A Strategic Approach to Digital Transformation in Manufacturing Industries

[16] Resego Morakanyane University College Cork, Audrey A. Grace University College Cork, Philip O'Reilly University College Cork, 2017, Conceptualizing Digital Transformation in Business Organizations: A Systematic Review of Literature

[17] https://www.panorama-consulting.com/whyculture-change-is-essential-for-digital-transformation/ [18] 13.https://www.bcg.com/capabilities/digitaltechnology-data/digital-transformation/how-to-drivedigital-culture

[22] https://www.ibm.com/topics/digital-transformation 